\title{
Research on the Implementation Status Quo of Vocal Music Curriculum of Music Major in Colleges and Universities
}

\author{
Xiang Peng ${ }^{1}$ \\ ${ }^{1}$ Aba Teachers University, Wenchuan, Sichuan, 623002
}

Keywords: implementation status quo; vocal music curriculum; Music Major; colleges and universities

\begin{abstract}
For a long time, the vocal music teaching in the music education of our country has always used the teaching model of the music academies, paying attention to the professionalism of the art performance and the individual qualities of students. The vocal students trained under this guiding goal are far away from the requirement of the education. This paper examines the current state of vocal music teaching in music education in Chinese colleges and universities and puts forward suggestions for these issues.
\end{abstract}

\section{Introduction}

In 2004, the Ministry of Education promulgated the guidance program of the music education professional education curriculum for music teachers in the general colleges and universities in the following. The "Course Project" clearly states that this specialty fosters the development of morality, intelligence, beauty, and beauty, and master basic theories, basic knowledge, and basic skills of music education. The article will use the "Course Program" and "National General Higher School Musicology Teacher Education Undergraduate Professional Course Teaching Guideline" from the Chinese colleges and universities music education vocal music teaching curriculum nature and objectives, course content The problems in the analysis of teaching methods, curriculum implementation and evaluation, etc., in order to adapt the vocal music teaching to the requirements of the times under the existing conditions.

\section{Analysis of the Core Connotation of Vocal Music Teaching}

The "vocal music" course teaching instruction outline clearly states in the nature of the curriculum that vocal music courses are professional compulsory courses established according to the needs of training music educators. Vocal music teaching is related to singing teaching in basic music education, and is integrated with knowledge and skills. Sexuality, artistry and practicality are all in one, and it is a major course for cultivating students' basic abilities in music teaching. Teacher's sexual requirements vividly require papers. This requires that the teaching of vocal music courses should be centered around cultivating students to become a qualified music educator. The characteristics of teacher education are reflected in many aspects in terms of the selection and refinement of teaching materials, and the arrangements and methods of teaching.

The teaching of music education professional vocal music courses should not only enable students to master the basic theory of vocal music to master the correct singing methods, but also have the ability to sing songs of different types. The correct analysis of the content and style of vocal music works and the processing of songs can be conducted in Putonghua and other necessary languages. As a vocal music education program for training basic music educators, students should also be able to identify the correctness of their vocalization, have the ability to independently teach songs and tutor outside vocal activities, and master vocal music teaching methods. It should also be able to understand the characteristics of adolescents' vocalization and master the relevant knowledge of voice-changing vocalization exercises and voice health care.

The explanation of the new "Course Program" emphasizes the need to adapt to the needs of the century's talents for music education, to improve the quality of music teaching professionals, and to 
set limits and optional courses to ensure the development of teacher education goals. The new outline points out that the teaching content of the music education major in colleges and universities should be closely integrated with the theoretical system of professional knowledge and basic education. The content of vocal music courses not only includes the basic concepts of vocal music, the structure and principles of vocalization, the form of singing of vocal music works, vocal techniques and vocal methods, authentic singing stance, vocal aesthetics and performance, vocal works appreciation and other vocal skills and theoretical knowledge. The study also includes students' teaching practice and evaluation, education of teenagers' voice and health care and vocal music teaching methods for teenagers. This not only emphasizes teacher-training but also reflects the comprehensiveness of the course content. Three curriculum teaching methods highlight diversity the new "Syllabus" according to the characteristics of music education professional vocal music teaching, according to the different content and form of teaching, detailed scientifically put forward the principles and methods of curriculum teaching. According to the theory of vocal music cultivation, vocal skill training, vocal music appreciation, and vocal singing, the combination of artistic and practical principles reflects the teaching content in the form of small lessons, group lessons, and large classes, and can be used to address individual differences among students. In the specific teaching, audio-visual data teaching method, mechanism teaching method, demonstration teaching method, independent teaching method, etc. are used to mobilize the students' interest in learning and create opportunities for the students to learn from each other and develop all-roundly. Especially for music teaching students, it is proposed that in the teaching of vocal music, we should adhere to the combination of classroom teaching with teaching practice and artistic practice, and pay attention to the overall improvement of students' teaching ability, practical ability and evaluation ability.

\section{Problems in Vocal Music Teaching of Music Education Majors in China's Colleges and Universities}

Since the establishment of music education in colleges and universities in the new-democratic era in China, the development in recent years has experienced a tortuous course of rise, interruption, restoration and development. It has made great achievements and promoted the continuous development and prosperity of music teaching in China's colleges and universities. Based on the combination of experience and its own characteristics, a set of teaching ideas that meet the conditions and requirements for vocal music education in China has been found. We must also see that although there is a systematic syllabus, a relatively rich curriculum, and documents, policies, and regulations that keep pace with the times, we have always attached great importance to the formation of professional theoretical literacy among students. However, the cultivation of basic education music teachers has been unable to keep up with the requirements of the times. The problems in the teaching of vocal music in the music education majors in universities and colleges in China are generally as follows.

At present, the vocal music teaching mode adopted by institutions of higher learning basically follows the vocal music teaching model of the existing professional music schools. Most of the textbooks used are classified as "Chinese works" or "foreign works" without a relatively clear graded learning. And teaching standards; Students' "learning" and teachers' "teaching" are highly random. However, the goal of professional music college vocal professional is to cultivate professional vocal talents. When students enter the school, most of them have a certain degree of singing skills and have received systematic professional training. What they need more is to improve their singing skills and stage manipulation skills. They can devote the main energy of learning to the vocal singing and skill mastering, so as to adapt to the professional teaching of arts groups or colleges and universities after graduation. The goal of music majors in institutions of higher learning is to cultivate the teachers of music and art courses in primary and secondary schools. They need to cultivate the comprehensive ability of students to sing, play, compile, teach and teach. At the same time, the vocal music foundation of these students when entering the school is also relatively weak. There is also a considerable gap between the level of singing and the 
professional foundation of the students of the professional music academy. The difference in student employment orientation and the difference in admission levels determine the students of music education majors in normal universities. In the four years of university, vocal music courses are just a part of many of their courses. Only by improving their comprehensive learning ability can they adapt to the future. This also determines that the learning time allocated to vocal music in teaching is very limited, and the purpose, content, mode, means and methods of teaching are totally different from those of professional singing and performing arts students. The current status quo is that there is almost no difference between the above two aspects. Due to the chaos and confusion of the training objectives, the students of the music education majors of the Normal University are generally fluctuate in their basic teaching and learning skills after graduating. This is already a common problem in the current professional audiovisual education in colleges and universities.

The development of a comprehensive and multi-angle compound talent requires a broad curriculum platform, which includes the comprehensiveness of the curriculum, the availability of vocal teachers, and the completeness of the vocal learning environment. For example, schools should be able to provide students with the opportunity, instruments and teachers needed for free practice. Because each vocal teacher's understanding of music is different from that of teaching, schools need to be able to provide students with comprehensive nutrients. Teachers' opportunities after a period of learning schools can provide students with zero-based learning conditions and have the opportunity to participate in performances every semester to create a strong atmosphere of vocal learning and performance, such as the periodical self-development by students. Opera performances, concerts and other forms of artistic performances in the opera performances, students participate in all aspects of rehearsals, performances, and props, and their singing is available in their native language. The treble can't be easily controlled by students and can be reduced.

However, looking at the development of music teaching in Chinese colleges and universities, we can clearly see that the position of vocal music courses in music art courses is low, and the proportion of vocal music-related courses in the total number of music art courses offered is about. This shows that the implementation advantages and value significance of vocal music teaching in music education in colleges and universities have not been fully understood, which has directly led teachers and students to pay insufficient attention to vocal music learning. Vocal music teaching has always been a weak link.

Since there is no universally consistent teaching material for the vocal music curriculum, the syllabus also advocates the construction of local curriculum resources and school-based curriculum, but the selection of curriculum content has no scientific argumentation criteria. The selection of the vocabulary curriculum is rather arbitrary, and the logical combination of learning content is not good. The learning and practice of students' partial vocal music knowledge is based on the learning of previous theoretical knowledge, and the jumping and difficulty of learning increase, which makes it difficult for students to receive complete vocal learning and construct a vocal knowledge system.

Theoretical learning is the foundation and soul of constructing subject knowledge. The internalization and sublimation of technical skills knowledge requires a firm theoretical basis. Vocal music as an abstract and technical discipline requires theoretical guidance and preparation. However, most of the vocal music classrooms of music education majors in universities in China are based on vocal skills and skills. They arrange excellent vocal music pieces and some opera arias in ancient and modern times, and the evaluation of learning is also based on skills. There is no effective vocal theory. College music majors train educators who adapt to basic music teaching. Vocal music theory is not only the basis for guiding elementary and middle school students to vocalize and sing, but also the basis for developing music teaching practice activities.

Similar courses in the "vocal music teaching method" have always been set up in college music professional teaching system, but the proportion of class hours is relatively small, teachers and students are not highly valued, and teaching effectiveness is limited. The pre-graduation education practice, because of short time, single form, feedback and evaluation mechanism is not perfect, has little effect on training and improving students' actual teaching ability. We are cultivating the basic 
music education workers in the future. The organizational ability, teaching ability and extracurricular coaching ability of vocal music teaching are the highlights of teacher education. Classrooms require outstanding musicians, but more need competent music teachers.

\section{Suggestions to Improve the Professional Vocal Music Teaching}

To improve the teaching of vocal music courses in music education majors in colleges and universities, it is necessary to take the new "Syllabus" and "Course Project" as the guide and proceed from the requirements of "exemplary", "comprehensiveness" and "diversity".

Aesthetic education is an important part of our country's school education. The aesthetic education at the basic education stage of primary and secondary schools is generally undertaken by the art curriculum. The music curriculum is naturally a very important part of it. Teachers are one of the important factors in the implementation of aesthetic education. The cultivation of music teachers in primary and secondary schools depends on the training of music professionals in institutions of higher learning. Vocal music curriculum is one of the contents of basic music teacher education and should be aimed at training music educators.

It is based on the teacher-orientated orientation of the vocal talent training target for music education. In the curriculum setting, the guidelines for the primary and secondary school curriculum should be taken as the yardstick, and the needs of the primary school should be used as compasses, and this goal should be reached in vocal music teaching. Students trained in vocal music teaching can not only sing, but also can know how to teach middle and primary school students to sing. Therefore, the two courses of vocal skills and vocal music basic theory are far from enough. It is also necessary to increase "vocal psychology", "vocal protection”, and "Singing physiology, common sense, folk songs and other courses lay the foundation for the basic skills of graduates.

Music is a performing art, but at the same time music education is a practical practice of educational practice. Teacher education requires that the students we cultivate are qualified teachers who can both teach and educate people, and qualified music talents who can sing on the stage. Therefore, on the one hand, universities should provide more opportunities for students to practice music performance arts and performance methods. Continuing and improving classroom teaching, on the other hand, students are encouraged to participate in practice activities such as internships, internships, fixed-point classes, designated counseling, or demonstration classes to avoid appearing in the teachers of primary and secondary schools.

\section{Conclusion}

The vocal music course in colleges and universities is a required course in the entire curriculum of music and education, and it is a basic course that fully reflects the comprehensive cultivation of music. With the continuous deepening of education and teaching reform, the reform and innovation of this basic discipline is of great significance in the times. It will surely promote the teaching reform and innovation of other music courses, and it will surely cultivate a more fully qualified music teacher to speed up the nationals.

\section{References}

[1] Yi Xiuhua. From the "Music Course Standard" on the vocal music teaching reform [J]. The Voice of the Yellow River, 2008, (15): 115.

[2] Yan Haiqing. On the Problems and Countermeasures of Vocal Music Teaching in Teachers Colleges [J]. Voices of the Yellow River, 2011, (2): 26

[3] Wang Anguo. Study on the Reform and Development of School Music Education in China [J]. Journal of Central Conservatory of Music, 2004, (4): 3. 